\title{
The role of Dickkopf-1 as a biomarker in systemic lupus erythematosus and active lupus nephritis
}

\author{
Mervat E. Abdelazeem', Marwa I. Abdelhaleem², Rabab A. Mohamed ${ }^{3}$ and Enas A. Abdelaleem ${ }^{1 *}$ (D)
}

\begin{abstract}
Background: Systemic lupus erythematosus (SLE) is a chronic disease which is mainly attributed to autoantibodies, cytokines, and immune complex deposition. Studies have demonstrated that cytokines and autoantibodies were strongly associated with renal diseases and can be used for the prediction of patients with lupus nephritis (LN). However, antibodies to dsDNA and the reduction of complements were also detected in non-LN patients as well as clinically non-active SLE patients. The current study was performed to detect the role of serum DKK-1 as a biomarker for the identification of SLE patients and patients with LN and its relation to disease activity and severity. The study was conducted on fifty clinically diagnosed SLE patients who were diagnosed according to Systemic Lupus International Collaborating Clinics (SLICC) classification criteria for SLE, in addition to thirty healthy control volunteers matched for age and sex. Assessment of SLE disease activity was done using Systemic Lupus Erythematosus Disease Activity Index (SLEDAI). Assessment of SLE disease severity was done using the Systemic Lupus International Collaborative Clinics/American College of Rheumatology (SLICC/ACR) damage index. Serum levels of DKK-1 were measured for all participants by ELISA using commercially available kits.

Results: DKK-1 serum levels were significantly higher among active lupus nephritis cases as compared with SLE cases with no LN and with healthy controls $(9197.60 \mu \mathrm{g} / \mathrm{uL} \pm 2939.2 \mu \mathrm{g} / \mathrm{uL}$ vs. $6405.15 \mu \mathrm{g} / \mathrm{uL} \pm 2018.91 \mu \mathrm{g} / \mathrm{uL}$ vs. $2790.33 \mu \mathrm{g} / \mathrm{uL} \pm 833.49 \mu \mathrm{g} / \mathrm{uL}$ ) respectively ( $p$-values $<0.001$ ). DKK-1 concentration was significantly higher among SLE patients with positive as compared with negative anti-double-stranded DNA (dsDNA) antibodies ( $p$-value $<$ 0.001). According to receiver operating characteristic (ROC) curve analysis, serum DKK-1 level diagnosed the SLE at a statistically significant level with a $98 \%$ sensitivity and $70 \%$ specificity and serum DKK-1 level also diagnosed active lupus nephritis at a $90 \%$ sensitivity and $63 \%$ specificity.

Conclusion: DKK-1 could diagnose SLE and lupus nephritis with high sensitivity and specificity. Serum DKK-1 is a reliable biomarker for the identification of SLE and patients with $L N$ and could be used as a key molecule for the diagnosis of SLE and as a prognostic indicator of LN.
\end{abstract}

Keywords: Systemic lupus erythematosus, Lupus nephritis, Dickkopf-1 protein

\footnotetext{
* Correspondence: dr.enas2000@gmail.com

'Rheumatology and Rehabilitation Department, Faculty of Medicine,

Beni-Suef University, Beni-Suef, Egypt

Full list of author information is available at the end of the article
}

\section{Springer Open}

(c) The Author(s). 2021 Open Access This article is licensed under a Creative Commons Attribution 4.0 International License, which permits use, sharing, adaptation, distribution and reproduction in any medium or format, as long as you give appropriate credit to the original author(s) and the source, provide a link to the Creative Commons licence, and indicate if changes were made. The images or other third party material in this article are included in the article's Creative Commons licence, unless indicated otherwise in a credit line to the material. If material is not included in the article's Creative Commons licence and your intended use is not permitted by statutory regulation or exceeds the permitted use, you will need to obtain permission directly from the copyright holder. To view a copy of this licence, visit http://creativecommons.org/licenses/by/4.0/. 


\section{Background}

Systemic lupus erythematosus (SLE) is a chronic inflammatory autoimmune illness that is characterized by generating numerous autoantibodies against auto-antigens [1]. The development of SLE pathogenesis can disturb various systems and multiple organs, among which lupus nephritis (LN) is one of the most common organ manifestations and the chief cause of illness and death in SLE patients [2].

The activity of renal disease is one of the most significant predictive issues for patients with SLE, and the documentation of LN in SLE patients thus has an important clinical consequence in the treatment of SLE [3].

Generally, SLE is known as a disease that is mainly due to autoantibodies, cytokines, and immune complex deposition. Studies have demonstrated cytokines and autoantibodies were strongly related to renal diseases and can be used for the prediction of patients with $\mathrm{LN}$ [3]. However, antibodies to dsDNA and the decrease of complements were also present in non-LN patients and clinically non-active SLE patients with a fairly high percentage [4].

This shortage of specificity of anti-dsDNA antibodies for renal activity was also noticed in other biomarkers [5], which thus headed to search for other consistent biomarkers for detecting SLE patients with active nephritis [6].

The Wnt signaling can be controlled by extracellular antagonists such as the Wnt inhibitory factor 1 (WIF1), Cerberus, and the Dickkopf (DKK) family of secreted proteins [7]. The DKK family contains four members of proteins, DKK-1, DKK2, DKK3, and DKK4, which are produced as antecedent proteins activated by a proteolytic cleavage [8]. The DKK-1 is considered the most important member of this family, which can hinder the Wnt signaling [9].

Human studies showed that the serum DKK-1 protein was significantly higher in SLE patients when compared with control individuals, associated by a high level of DKK-1 in the renal tissues and an increased incidence of apoptotic cells of the renal tubular and renal interstitial tissues [10].

Many studies have detected the possibly diagnostic and/or prognostic values of DKK-1 in rheumatic disorders [11]. Together with the pathogenic roles of Wnt signaling in LN development, these studies obviously suggest that Wnt signaling, in specific the DKK-1, may be a unique biomarker for the identification of $\mathrm{LN}$ for patients with SLE.

The aim of the current study was to detect the role of circulating DKK-1 as a biomarker for the identification of SLE patients and patients with LN and its relation to disease activity and severity.

\section{Methods}

\section{Study design}

The present study was a case-control study conducted on fifty clinically diagnosed SLE patients (2 males and 48 females) who were selected from Rheumatology \&Rehabilitation Department from March 2019 to March 2020 and diagnosed according to Systemic Lupus International Collaborating Clinics (SLICC) classification criteria for SLE [12], in addition to thirty healthy control volunteers matched in age and sex (4 males and 26 females). Consents were obtained from the patients and controls after approval by the local ethical committee.

Inclusion criteria were age $>17$ years (males and females were included). An active LN was defined as urine protein excretion $\geq 500 \mathrm{mg} /$ day or cellular casts.

Exclusion criteria were patient's refusal, patients with other rheumatological diseases, or patients with chronic kidney disease for causes other than SLE.

\section{Patients' assessment}

All patients were subjected to full clinical and laboratory investigations $(\mathrm{CBC}$, ESR CRP, creatinine, urea, serum cholesterol, complete urine analysis, 24-h urinary proteins, ANA, anti-dsDNA, C3, and C4). Renal biopsy was done if indicated and classified according to the classification of lupus nephritis by the International Society of Nephrology/Renal Pathology Society (ISN/RPS) [13].

Assessment of SLE disease activity was done using Systemic Lupus Erythematosus Disease Activity Index (SLEDAI) which measures disease activity within the last 10 days. It includes 24 clinical and laboratory variables that are weighted by the type of manifestation, but not by the severity [14].

Assessment of SLE disease severity was done using the Systemic Lupus International Collaborative Clinics/ American College of Rheumatology (SLICC/ACR) damage index which is a measurement of cumulative endorgan damage in SLE. It is not related to active inflammation, occurring since the onset of lupus, ascertained by clinical assessment [15].

\section{Detection of DDK-1 for all participants by ELISA}

Concentrations of DKK-1 proteins in serum were measured by ELISA using commercially available kits according to the manufacturer's instructions.

\section{Statistical methods of analysis}

The collected data were coded then entered and analyzed using the Statistical Package for Social Sciences (SPSS) computer software (version 25), IBM software, USA.

Descriptive statistics was done for categorical variables by frequency and percentage and for numerical variables in the form of mean and standard deviation (mean $\pm \mathrm{SD}$ ). 
Suitable statistical tests of significance were used: independent sample $t$ test for two unrelated samples, oneway ANOVA test for more than two related samples, and post hoc (LSD) analysis to identify which pairs of means were statistically different, chi-square $\left(\chi^{2}\right)$ test for categorical data, and Pearson correlation analysis; and receiver operator characteristic (ROC) curve was used to find out the best cutoff value and validity of certain variable. $p$-values equal to or less than 0.05 were considered statistically significant.

\section{Results}

The present study was a case-control study conducted on two matched groups: SLE patients and controls; their demographic data are presented in Table 1. Renal biopsies for twenty patients in the present study showed eight cases $(40 \%)$ were with class III, eight cases $(40 \%)$ with class IV, two cases (10\%) with class II, one case (5\%) with class I, and one case (5\%) with class V.

All the fifty SLE patients involved in the present study were on steroid dose ranged from 5 to $60 \mathrm{mg}(\mathrm{mg} /$ day) with a mean dose of $20.80 \pm 15.3$. Hydroxychloroquine was used by 45 (89.8\%) SLE patients, 3 cases of them (10\%) on dose $200 \mathrm{mg}$ while the majority of cases were on dose $400 \mathrm{mg}$ (two pills per day) with no statistically significant differences between active lupus nephritis cases and other SLE cases $(p$-value $=0.943)$. Azathioprine $($ Imuran $)$ was prescribed for 27 cases only (54\%) among the studied SLE patients. They were significantly more frequently prescribed for active lupus nephritis cases.

Serum creatinine level was significantly higher among cases with active lupus nephritis as compared with other SLE cases $(p$-value $=0.025)$. Urea was significantly higher among cases with active lupus nephritis as compared with other SLE cases ( $p$-value $=0.023$ ).

Serum cholesterol level was significantly higher among cases with active lupus nephritis as compared with other SLE cases $(p$-value $=0.002)$. However, no significant differences were detected regarding other lipid profile parameters between active lupus nephritis and other SLE cases in the present study ( $p$-value $=0.825,0.067$, and 0.577).
Antinuclear antibody (ANA) was positive among all SLE patients involved in our study. Anti-doublestranded DNA (dsDNA) antibodies were positive in 21 $(42 \%)$ cases of the involved SLE patients, only one case with no lupus nephritis, and the remaining 20 cases were active lupus nephritis with a statistically significant difference between both groups ( $p$-value $<0.001$ ).

Complement C3 ranged from 14 to 160 with a mean of $96.81 \pm 28.28(\mathrm{mg} / \mathrm{dL})$. Complement $\mathrm{C} 4$ ranged from 2 to 35 with a mean of $20.35 \pm 7.91(\mathrm{mg} / \mathrm{dL})$ in SLE patients with no lupus nephritis, while in SLE patients with active lupus nephritis C3 ranged from 14 to 172 with a mean of $87.80 \pm 45.91(\mathrm{mg} / \mathrm{dL})$ and $\mathrm{C} 4$ ranged from 2 to 99 with a mean of $20.24 \pm 20.35(\mathrm{mg} / \mathrm{dL})$ with no statistically significant difference between patients with LN and patients without LN ( $p$-values $=0.394,0.979)$.

The SLICC damage index score showed no damage in 41 cases $(82 \%)$ and damage only in 9 cases $(18 \%)$, while the SLEDAI score for the studied SLE patients ranged from 4 to 35 with a mean score of $17.38 \pm 7.6$ with no statistically significant difference between patients with LN and patients without LN.

DKK-1 level was significantly highest among active lupus nephritis cases as compared with SLE cases with no LN and with healthy controls $(9197.60 \mu \mathrm{g} / \mathrm{uL} \pm$ $2939.2 \mu \mathrm{g} / \mathrm{uL}$ vs. $6405.15 \mu \mathrm{g} / \mathrm{uL} \pm 2018.91 \mu \mathrm{g} / \mathrm{uL}$ vs. $2790.33 \mu \mathrm{g} / \mathrm{uL} \pm 833.49 \mu \mathrm{g} / \mathrm{uL})$ respectively, $p$-values < 0.001 (Fig. 1).

DKK-1 serum level comparison according to different symptoms and signs showed significant differences with arthritis/arthralgia only (Table 2).

DKK-1 concentration was significantly higher among SLE patients with positive anti-double-stranded DNA (dsDNA) antibodies as compared with SLE patients with negative dsDNA antibodies among the studied SLE patients ( $p$-value $<0.001$ ) (see Fig. 2).

No correlation was detected between patients' age, disease duration, prednisolone dose used in the management of SLE, and the concentration of DKK-1 among studied SLE patients. Also, no significant correlation was detected with any of the laboratory investigations (CBC, ESR, CRP, lipids). No significant correlation was detected with both

Table 1 DKK1 serum level among studied population

\begin{tabular}{|c|c|c|c|c|}
\hline & \multicolumn{3}{|l|}{ Studied Population } & \multirow[t]{2}{*}{$p$-value } \\
\hline & $\begin{array}{l}\text { SLE Patients } \\
\text { (No Lupus Nephritis) } \\
N=30\end{array}$ & $\begin{array}{l}\text { SLE Patients } \\
\text { (Active Lupus Nephritis) } \\
N=20\end{array}$ & $\begin{array}{l}\text { Healthy Controls } \\
N=30\end{array}$ & \\
\hline Mean \pm SD & $6405.15 \pm 2018.91^{b, c}$ & $9197.60 \pm 2939.2^{a, c}$ & $2790.33 \pm 833.49^{a . b}$ & $<0.001^{*}$ \\
\hline Minimum & 1050.60 & 4244.00 & 1150.00 & \\
\hline Maximum & 9752.00 & 13640.00 & 4516.00 & \\
\hline
\end{tabular}

Statistical analysis was carried out using one-way analysis of variance (ANOVA) followed by LSD post hoc analysis. ${ }^{*} p$-value $\leq 0.05$ is considered significant

a Significantly different from SLE Patients (No Lupus Nephritis) at $p$-value $<0.05$

${ }^{b}$ Significantly different from Active Lupus Nephritis at p-value $<0.05$

c Significantly different from Healthy Controls at $p$-value $<0.05$ 


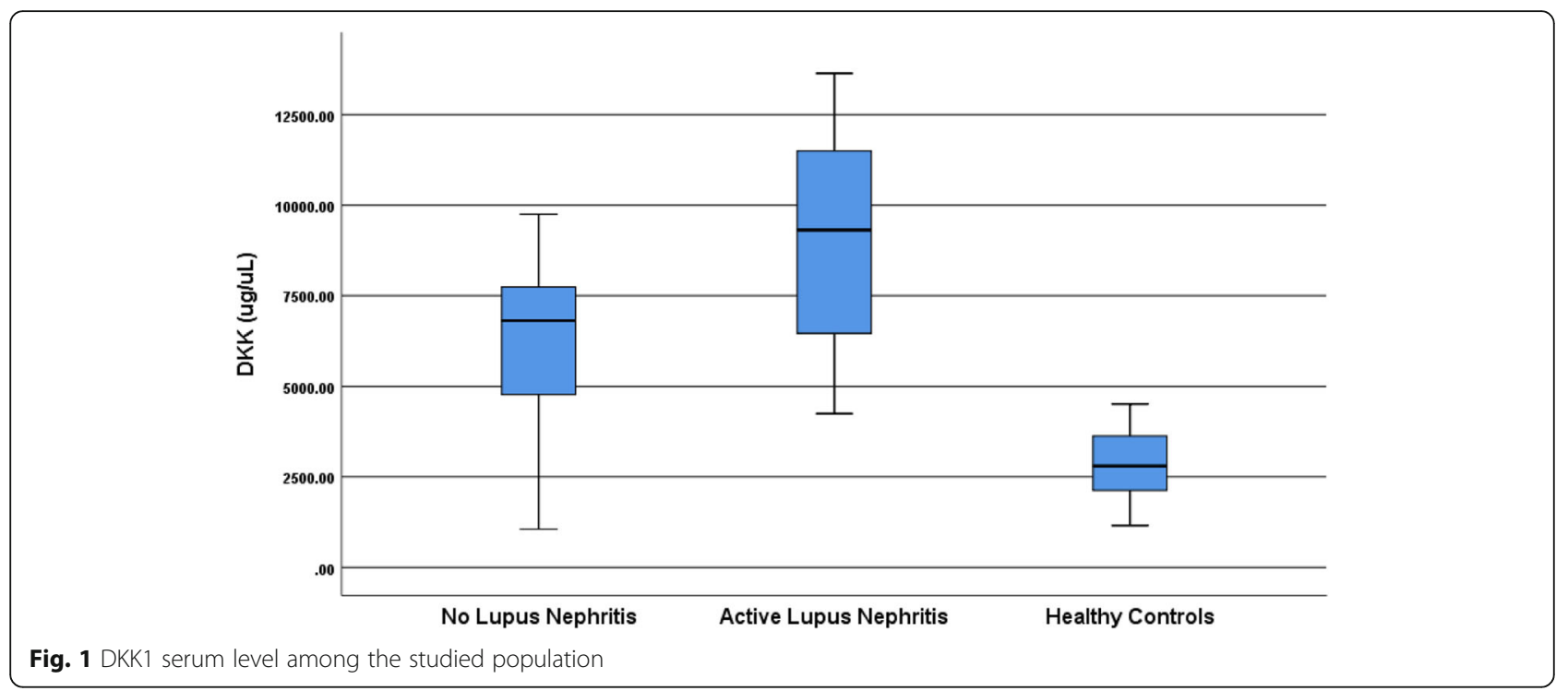

neither C3 nor C4 and the concentration of DKK-1 among studied SLE disease patients. The concentration of DKK-1 showed a non-significant correlation neither with disease activity by SLEDAI score nor with SLICC damage index score among studied SLE patients.

As demonstrated in Table 3 and Fig. 3, the receiver operating characteristic (ROC) curve analysis was used to assess the clinical diagnostic accuracy of DKK-1 in SLE disease and the normal individuals; the results of DKK-1 (ROC) curve analysis showed $p$-value $<0.05$, so the serum DKK-1 level diagnosed the SLE disease state at a statistically significant level with a $98 \%$ sensitivity (true positive cases) and $70 \%$ specificity (true negative cases) at a cutoff point level $\geq 3160.00$.

As demonstrated in Table 4 and Fig. 4, ROC curve analysis was used to assess the clinical diagnostic accuracy of DKK-1 in active lupus nephritis and the normal individuals; the results of DKK-1 (ROC) curve analysis showed $p$-value $<0.05$, so the serum DKK-1 level diagnosed the lupus nephritis state at a statistically significant level with a $90 \%$ sensitivity (true positive cases) and $63 \%$ specificity (true negative cases) at a cutoff point level $\geq 6010.00$.

Table 2 Comparison of DKK-1 concentration in Anti-double strand DNA positive and Anti-double strand DNA negative in Studied SLE Patients; $(N=50)$

\begin{tabular}{llll}
\hline & $\begin{array}{l}\text { DKK-1 } \\
\text { concentration } \\
\text { Mean } \pm \text { SD }\end{array}$ & p-value \\
\hline ds-DNA & No; $\boldsymbol{n}=\mathbf{2 9}$ & $6309.40 \pm 1984.12$ & $\mathbf{0 . 0 0 1 *}$ \\
& Yes; $\boldsymbol{n}=\mathbf{2 1}$ & $9196.86 \pm 2864.78$ & \\
\hline
\end{tabular}

${ }^{*} p$-value $\leq 0.05$ is considered statistically significant

\section{Discussion}

Lupus nephritis is a common and serious complication of SLE which progresses to end-stage renal disease. Several key molecules have been investigated as biomarkers for disease diagnosis and prognosis among which is DKK-1 [16].

We performed this study to detect the value of serum DKK-1 as a biomarker for the detection of patients with SLE and patients with LN and its relation to disease activity and severity.

The majority of the studied SLE patients in our study were females $(94 \%)$ where only $6 \%$ were males with a female to male ratio of nearly $16: 1$ and the mean age for our patients was $28.98 \pm 6.8$ years old. SLE has long been viewed as a disease primarily of young females with a young age at onset of the disease [17].

Anti-double-stranded (ds) DNA autoantibody is a useful tool in the evaluation of disease activity and nephritis in systemic lupus erythematosus (SLE) patients. Antibodies to dsDNA and the reduction of complements C3 and C4, which are considered indicators for renal affection and activity, were also detected in patients without LN and patients with clinically inactive SLE with a comparatively high proportion [18]. In our study, there was no statistically significant difference in complements C3 and C4 among patients with active $\mathrm{LN}$ and patients without. On the other hand, in the present study, anti-double-stranded DNA (dsDNA) antibodies were positive in 21 cases of the involved SLE patients, only one case with no lupus nephritis and the remaining 20 cases were active lupus nephritis with a statistically significant difference between both groups ( $p$-value $<0.001$ ). This result is considered consistent with the other studies, which found that antibodies such as anti-double-stranded (ds) DNA antibodies have 


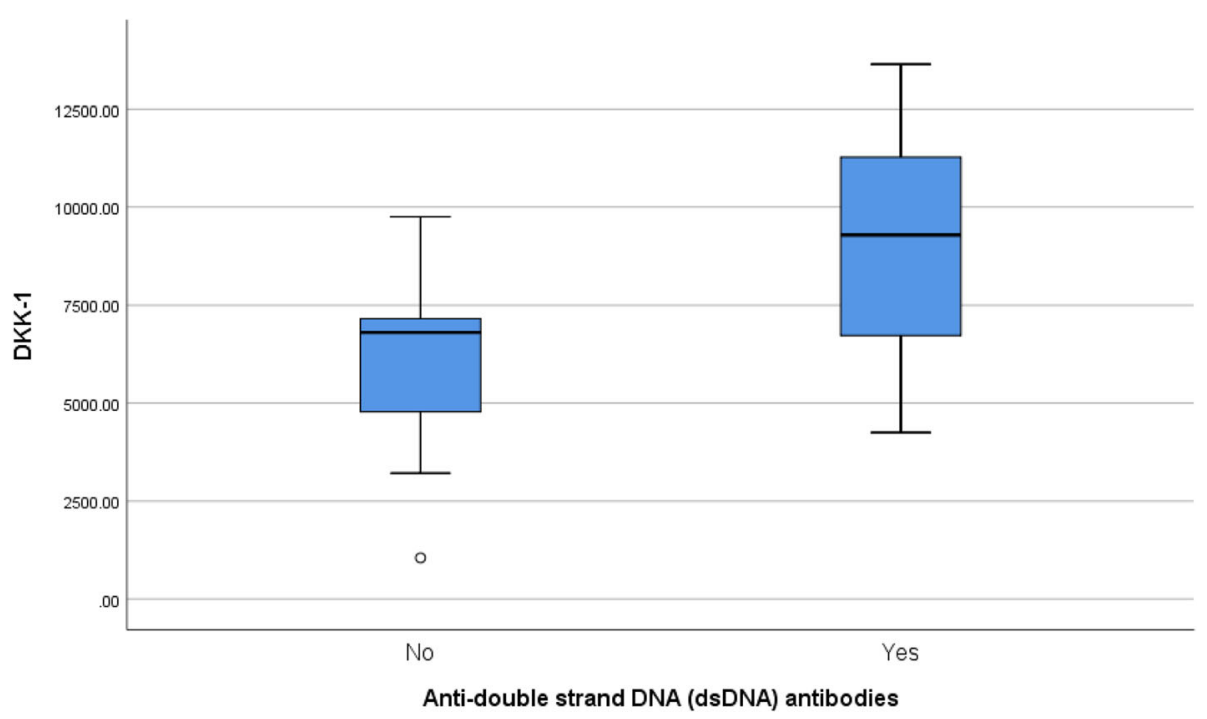

Fig. 2 Relation of anti-double-stranded DNA (dsDNA) and DKK-1 concentration among SLE patients

been shown to associate with renal involvement in lupus patients [19-21].

In the present study, patients with active LN were significantly more often on immune-suppressive drugs as compared with patients without active LN. This result came in agreement with $\mathrm{Sj}$ wall and his colleagues who studied 261 SLE patients (37 of them were with active $\mathrm{LN}$ ), where active LN patients were more often on mycophenolate mofetil (immunosuppressive) [22].

SLE disease activity and severity were assessed by SLEDAI score and SLICC damage index score in our study and revealed no statistically significant difference between both studied patients' groups (with and without active LN); this was near to that reported by Sjöwall and his colleagues as no statistically significant difference in SLICC damage index score between studied patients with and without active LN; however, in their study, SLEDAI score was significantly higher among patients with active LN [22].

Renal biopsies in our study showed eight cases (40\%) were with class III, eight cases (40\%) with class IV, two cases (10\%) with class II, one case (5\%) with class I, and one case (5\%) with class V (serum levels of Dicopf-1 comparison between different grades were not done due to the small number of each subgroup). The higher frequency of class III and IV LN in this study might be owing to the late presentation and the significant association between symptoms and signs with these classes at presentation. Our percentages were close to those of
Somers et al., who reported $40 \%$ class III and 35\% class IV of their studied patients [23]. This is also similar to Mahgoub et al., who reported $50 \%$ had LN grade III and $30 \%$ had LN grade IV [18].

The concentration of DKK-1 proteins was assessed in SLE patients' serum and in healthy control subjects by ELISA technique. The results revealed that a significant increase of DKK-1 protein was detected in sera of SLE patients compared with healthy controls ( $p$-value $<0.001$ ). The serum DKK-1 concentration was higher in LNSLE patients in comparison with non-LN-SLE subjects ( $p$-value $<0.001)$.

The effect of DKK1 has been studied in renal involvement among SLE patients. In 97 SLE patients from a hospital in Shanghai who were referred for renal biopsy, hyper-activation of the Wnt pathway in relation to healthy individuals and patients with some types of renal tumors was found. The abovementioned results were confirmed by elevation in the intensity of p-catenin staining by immunohistochemistry of the glomeruli in the renal biopsies, increased levels by Western blot and by reverse transcription polymerase chain reaction (RTPCR), as well as an elevation in AXIN-2 and DKK-1, which are part of the elements of response at the end of the signaling pathway, and finally, increase in serum DKK-1 measured by ELISA [24].

In the SLE disease, dysregulated Wnt signaling activity was first detected in sera and kidneys of mice during lupus development by gene expression analysis. This

Table 3 The results of ROC curve analysis of DKK-1 in the studied SLE and normal population

\begin{tabular}{llllllll}
\hline & AUC & SE & $\mathbf{9 5 \% ~ C l}$ & Sensitivity & Specificity & Cutoff value & $\boldsymbol{p}$-value \\
\hline DKK-1 & 0.968 & 0.021 & $0.926-1.000$ & $98 \%$ & $70 \%$ & $\geq 3160.00$ & $<0.001$ \\
\hline
\end{tabular}

AUC Area under the curve, SE Standard Error, CI Confidence interval of AUC 


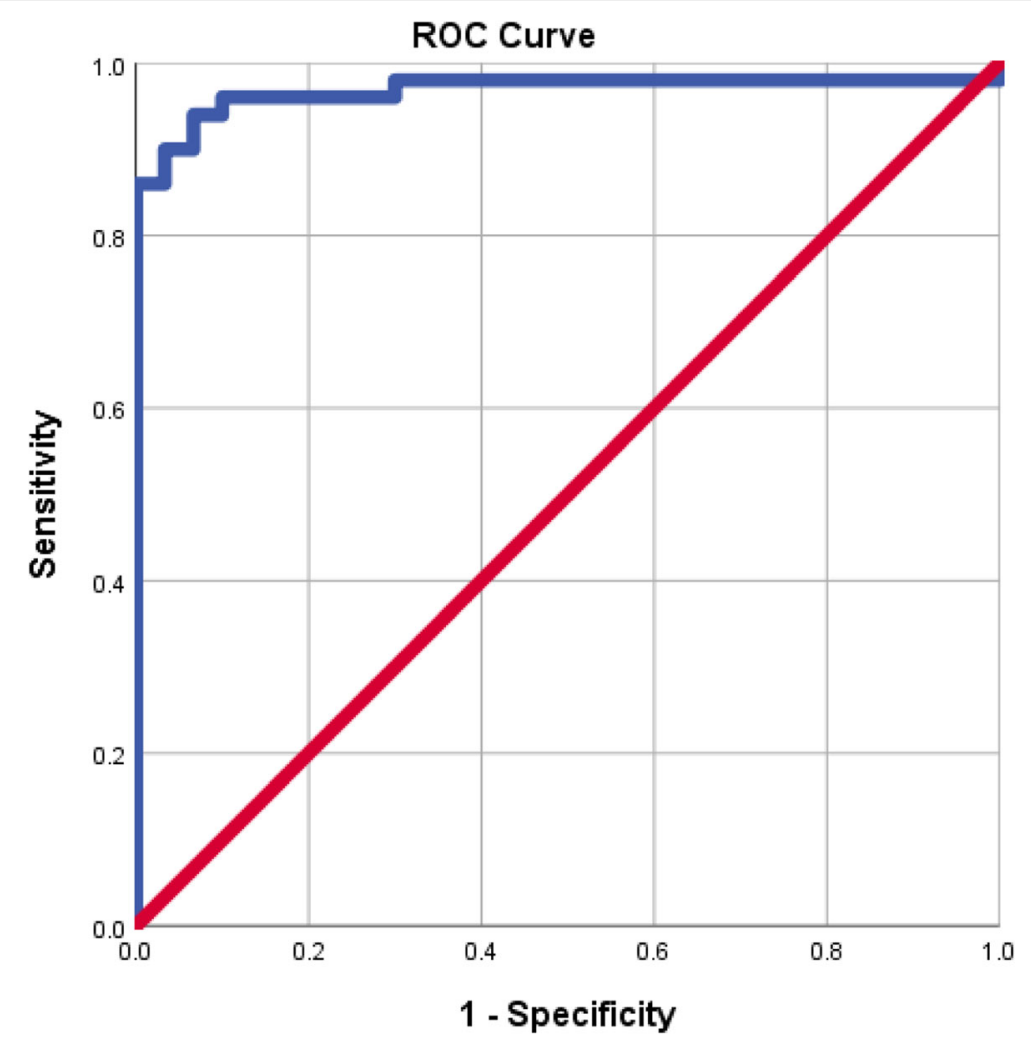

Fig. 3 The results of ROC curve analysis of DKK-1 in the studied SLE and normal population

study thus indicated that Wnt signaling activity was boosted in the kidney with LN, which was associated with increased renal and serum DKK-1 levels, signifying that the canonical Wnt signaling was involved in the turnover of extracellular matrix components and denotes a valuable mediator of the morphologic changes that occur inside the glomerulus throughout the development of nephritis, and the DKK-1 might be a critical element in the development and evolution of systemic and end-organ failure in SLE [25].

Wang et al. [26] reported increased activation of Wnt/ $\beta$-catenin signaling in SLE patients with LN. In their study, they assessed the expressions of $\beta$-catenin, DKK1 , and AXIN-1 mRNAs and proteins in the renal biopsy from patients with LN-SLE by a quantitative RT-PCR and immunohistochemistry assay, respectively; the concentration of plasma DDK-1 was also measured by ELIS A. A significantly higher concentration of serum DKK-1 protein was found in LN patients in relation to healthy controls [26].
In agreement with the above findings, a similar study measured serum DKK-1 in 111 SLE patients (31 with $\mathrm{LN}$ and 80 without $\mathrm{LN}$ ) and 70 healthy volunteers; an elevated concentration of DKK-1 was determined in the serum of SLE patients in relation to healthy individuals. Significantly higher levels of serum DKK-1 were detected in LN-SLE patients compared to those with non-LNSLE [27].

In our study, DKK-1 concentration was significantly higher among SLE patients with positive dsDNA antibodies as compared with SLE patients with negative dsDNA antibodies. This finding was on the contrary with Xue et al. 2017 who reported no significant correlation between concentrations of serum or urine DKK-1 anti-dsDNA antibody; in their study, anti-dsDNA was higher among active LN but with no statistically significant differences, $p$-value $=0.054$ [27]. In our study, there was no significant correlation between the concentration of serum DKK-1 and C3 and C4; the same was reported by Xue et al. [27].

Table 4 The results of ROC curve analysis of DKK-1 in the studied Active Lupus Nephritis and normal population

\begin{tabular}{llllllll}
\hline & AUC & SE & $95 \%$ Cl & Sensitivity & Specificity & Cutoff value & $\boldsymbol{p}$-value \\
\hline DKK-1 & 0.874 & 0.041 & $0.793-0.954$ & $90 \%$ & $37 \%$ & $\geq 6010.00$ & $<0.001$ \\
\hline
\end{tabular}

AUC Area under the curve, SE Standard Error, CI Confidence interval of AUC 


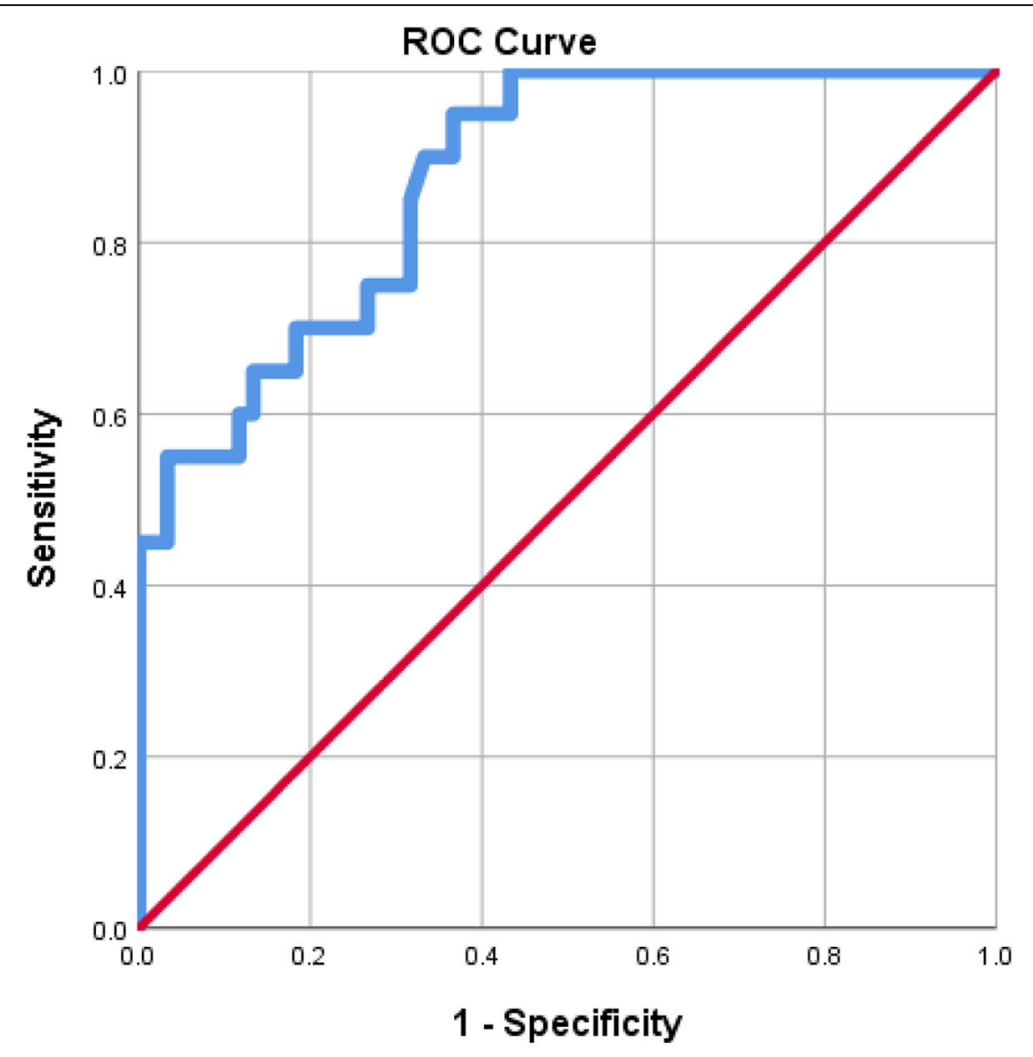

Diagonal segments are produced by ties.

Fig. 4 The results of ROC curve analysis of DKK-1 in the studied active lupus nephritis and normal population

The concentration of DKK-1 showed a non-significant correlation with disease activity assessed by SLEDAI score among studied SLE patients. No relation was detected between SLICC damage index score and DKK-1 concentration among the studied SLE patients. Those findings were in accordance with Wang et al. [26] study where DKK-1 did not seem to be correlated with clinical parameters, including disease activity, assessed by SLEDAI and SLICC damage index score SLE [26].

DKK-1 showed unexpected lower levels in our patients with arthralgia/arthritis than those without which warranted further studies as DKK is known to be secreted in synovial fluid.

The ROC curve analysis showed that serum DKK-1 was considered a better positive independent biomarker than negative in SLE and LN with higher sensitivity. Those findings were in accordance with Wang et al. study, which concluded that the serum DKK-1 was considered a better positive biomarker for identification of LN in SLE patients [26].

The current study has some limitations presented such as the small number of participants and consequently for each group and we could not do the correlation according to the results of renal biopsy.
Further researches with larger numbers of patients are recommended to illuminate the role of DKK-1 as an independent biomarker in SLE patients. We recommend it to be measured not only in serum but also in urine and synovial fluid.

\section{Conclusion}

DKK-1 could diagnose SLE and lupus nephritis with high sensitivity and specificity. Serum DKK-1 is a reliable biomarker for the identification of SLE and patients with LN and could be used as a key molecule for the diagnosis of SLE and as a prognostic indicator of LN.

\section{Abbreviations}

DKK-1: Dickkopf-1; LN: Lupus nephritis; SLE: Systemic lupus erythematosus; SLICC: Systemic lupus international collaborating clinics

\section{Acknowledgements \\ To all the patients and control.}

\section{Authors' contributions}

$\mathrm{Ml}$ collected the data from the patients and control, performed the examination, and was involved in writing the manuscript. EA is the corresponding author and was involved in analyzing the data and writing the manuscript. ME participated in assessing the patients and writing the manuscript. RA performed the laboratory investigations mainly Dickkopf-1. All authors have read and approved the final manuscript. 
Funding

Not applicable

\section{Availability of data and materials}

Available on reasonable request

\section{Ethics approval and consent to participate}

Verbal/written consents were obtained from the patients and from controls and were approved by the ethical committee of the Faculty of Medicine, Beni-Suef University. The reference number is FMBSUREC/05032019/ AL Haleem

\section{Consent for publication}

Not applicable

\section{Competing interests}

The authors declare no competing interests.

\section{Author details}

'Rheumatology and Rehabilitation Department, Faculty of Medicine, Beni-Suef University, Beni-Suef, Egypt. ${ }^{2}$ Rheumatology and Rehabilitation Department, Beni-Suef General Hospital, Beni-Suef, Egypt. ${ }^{3} \mathrm{Clinical}$ Pathology Department, Faculty of Medicine, Beni-Suef University, Beni-Suef, Egypt.

Received: 16 December 2020 Accepted: 8 February 2021

Published online: 05 March 2021

\section{References}

1. Yap DYH, Lai KN (2015) Pathogenesis of renal disease in systemic lupus erythematosus - the role of autoantibodies and lymphocytes subset abnormalities. Int J Mol Sci 16(4):7917-7931

2. Moroni G, Quaglini S, Radice A, Trezzi B, Raffiotta F (2015) The value of a panel of autoantibodies for predicting the activity of lupus nephritis at time of renal biopsy. J Immunol Res. 2015:106904. https://doi.org/10.1155/2015/1 06904

3. Hong S, Healy H, Kassianos AJ (2020) The emerging role of renal tubular epithelial cells in the immunological pathophysiology of lupus nephritis. Front Immunol. https://doi.org/10.3389/fimmu.2020.578952

4. Dumestre PC, Clavarino G, Colliard S, Cesbron JY, Thielens NM (2018) Antibodies targeting circulating protective molecules in lupus nephritis: interest as serological biomarkers. Autoimmun Rev 17(9):890-899

5. Adhya Z, El Anbari M, Anwar S, Mortimer A, Marr N (2019) Soluble TNF-R1, VEGF and other cytokines as markers of disease activity in systemic lupus erythematosus and lupus nephritis. Lupus 28(6):713-721

6. Marto N, Bertolaccini ML, Calabuig E, Hughes GR, Khamashta MA (2005) Anti-C1q antibodies in nephritis: correlation between titres and renal disease activity and positive predictive value in systemic lupus erythematosus. Ann Rheum Dis 64(3):444-448

7. Malinauskas T, Jones EY (2014) Extracellular modulators of Wnt signalling Cur Opin Struct Biol 29:77-84

8. Niehrs C (2006) Function and biological roles of the Dickkopf family of Wnt modulators. Oncogene 25(57):7469-7481

9. Liang B, Zhong L, He Q, Wang S, Pan Z (2015) Serum dickkopf-1 as a biomarker in screening gastrointestinal cancers: a systematic review and meta-analysis. OncoTargets Ther 8:3115

10. Long L, Liu Y, Wang S, Zhao Y, Guo J (2010) Dickkopf-1 as potential biomarker to evaluate bone erosion in systemic lupus erythematosus. J Clin Immunol 30(5):669-675

11. Rossini M, Viapiana O, Adami S, Fracassi E, Idolazzi L et al (2015) In patients with rheumatoid arthritis, Dickkopf-1 serum levels are correlated with parathyroid hormone, bone erosions and bone mineral density. Clin Exp Rheumatol 33(1):77-83

12. Petri M, Orbai AM, Alarcón GS, Gordon C, Merrill JT et al (2012) Derivation and validation of the Systemic Lupus International Collaborating Clinics classification criteria for systemic lupus erythematosus. Arthritis Rheum 64(8):2677-2686

13. Weening JJ, D'Agati VD, Schwartz MM, Seshan SV, Alpers CE et al (2004) The classification of glomerulonephritis in systemic lupus erythematosus revisited. J Am Soc Nephrol 15(2):241-250
14. Rovenský J, Payer J (2009) Systemic lupus erythematosus disease activity index (SLEDAI). In: Dictionary of Rheumatology. Springer Vienna, Vienna, pp 209-209

15. Gladman D, Ginzler E, Goldsmith C, Fortin P, Liang M et al (1996) The development and initial validation of the Systemic Lupus International Collaborating Clinics/American College of Rheumatology damage index for systemic lupus erythematosus. Arthritis Rheum 39(3):363-369

16. Bates MA, Akbari P, Gilley KN, Wagner JG, Li N, Kopec AK et al (2018) Dietary docosahexaenoic acid prevents silica-induced development of pulmonary ectopic germinal centers and glomerulonephritis in the lupus-prone NZBWF1 mouse. Front Immunol 2002. https://doi.org/10.3389/fimmu.2018. 02002

17. Lim SS, Bayakly AR, Helmick CG, Gordon C, Easley KA et al (2014) The incidence and prevalence of systemic lupus erythematosus, 2002-2004: The Georgia Lupus Registry. Arthritis Rheumatol 66(2):357-368

18. Mahgoub MY, Foda Al, Elshambaky AY, Abdelrahman AM, Nasif SN et al (2018) Renalase and lupus nephritis: disease activity and histopathological classification. Egypt Rheumatol Rehabil 45(4):175

19. Jaekel HP, Trabandt A, Grobe N, Werle E (2006) Anti-dsDNA antibody subtypes and anti-C1q antibodies: toward a more reliable diagnosis and monitoring of systemic lupus erythematosus and lupus nephritis. Lupus 15(6):335-345

20. Soliman S, Mohan C (2017) Lupus nephritis biomarkers. Clin Immunol 185: 10-20

21. Bentow C, Lakos G, Martis P, Wahl E, Garcia M et al (2016) International multi-center evaluation of a novel chemiluminescence assay for the detection of anti-dsDNA antibodies. Lupus 25(8):864-872

22. Sjöwall C, Bentow C, Aure MA, Mahler M. Two-Parametric immunological score development for assessing renal involvement and disease activity in systemic lupus erythematosus. J Immunol Res. 2018;2018(2):1-9

23. Somers EC, Marder W, Cagnoli P, Lewis EE, DeGuire P et al (2014) Population-based incidence and prevalence of systemic lupus erythematosus: the Michigan Lupus Epidemiology and Surveillance program. Arthritis Rheumatol 66(2):369-378

24. Hu TH, Yao Y, Yu S, Han LL, Wang WJ et al (2014) SDF-1/CXCR4 promotes epithelial-mesenchymal transition and progression of colorectal cancer by activation of the Wnt/ß-catenin signaling pathway. Cancer Lett 354(2):417-426

25. Tveita AA, Rekvig OP (2011) Alterations in Wnt pathway activity in mouse serum and kidneys during lupus development. Arthritis Rheum 63(2):513-522

26. Wang X-d, Huang X-f, Yan Q-r (2014) Aberrant activation of the WNT/Bcatenin signaling pathway in lupus nephritis. PLoS One 9(1):e84852

27. Xue J, Yang J, Yang L, Zhou S, Ji C, Wang $X$ et al. Dickkopf- 1 is a biomarker for systemic lupus erythematosus and active lupus nephritis. J Immunol Res 2017;2017:6861575

\section{Publisher's Note}

Springer Nature remains neutral with regard to jurisdictional claims in published maps and institutional affiliations.

\section{Submit your manuscript to a SpringerOpen ${ }^{\circ}$ journal and benefit from:}

- Convenient online submission

- Rigorous peer review

- Open access: articles freely available online

- High visibility within the field

- Retaining the copyright to your article

Submit your next manuscript at $>$ springeropen.com 